\title{
The Relativity of Hydrostatic Impact on Timber and Engineered Materials
}

\author{
Aliu. A.O \\ Department of Civil Engineering Technology \\ Rufus Giwa Polytechnic, \\ Owo, Ondo State, Nigeria
}

\author{
Fakuyi. F \\ Department of Civil Engineering Technology \\ Rufus Giwa Polytechnic, \\ Owo, Ondo State, Nigeria
}

\begin{abstract}
This research work was done in other to compare the relative impact of water absorption on both solid wood and engineered wood materials. The materials tested were: MDF, Chipboard, Plywood (Engineered Wood Materials) and Mahogany and Cordia (Solid Wood). Each material measuring $125 \mathrm{~mm} \times 15 \mathrm{~mm} \times 15 \mathrm{~mm}$ was subjected to full water immersion under same Equilibrium Moisture Content (EMC) atmosphere. The weight of the materials were recorded before immersion and at every interval of 30minutes under immersion, the change in mass was recorded and calculated for individual material. It was observed that both MDF and Chipboard absorbed water at a high rate of between 60.6-64\% respectively compared to the plywood with little change of $37.89 \%$ to the initial value. However, the absorption for solid wood is very low as observed in the first 30mins duration compared to the engineered boards. Therefore, it was recommended that since the solid woods are resistant to water absorption than the engineered composite boards, they are more suited for outdoor works where exposure to moisture rise will be significant. However, plywood can equally be used if it is of structural or marine grade regardless of the prevailing EMC. Building and furniture materials with significant water body are greatly affected by defects that reduce the strength, durability and appearance.
\end{abstract}

Keywords- Relative Humidity, EMC, Engineered Boards, Wood, Hydrostatic Action, Water Absorption

\section{INTRODUCTION}

Timber and its composites have always served as good materials for furniture and building construction, especially for its durability, aesthetics and other properties. However, due to seasonal changes in climatic condition, there arose the possibility of these wooden materials being subjected to consistent hydrostatic action during the rainy days [1]. Solid wood is hygroscopic because its moisture content fluctuates naturally based on the relative humidity. There is the need to understand the effect of the waterbody on solid wood and engineering wood composites so as to proffer a lasting solution to any negative effect that may arise when carrying out building or furniture works. The presence of excess moisture in timber has lots of adverse effects for construction purposes [2]. The percentage moisture content equally affects both the physical and mechanical properties when it changes below the EMC. The ranking order of materials in their sensitivity to alternating temperature differs to that under alternating humidity [3].

Engineered wood is an improvement on the natural arrangement of tissues and tracheid that produce natural wood fibres. Wood is made up of tannins, toxins, dyes, acids and wax which develop into the moisturised sap of the wood. Naturally, the fibres are lignified together to form a bundle-like hard structure useful for both furniture and building works [4]. Engineered wood includes a range of derivative wood products which are manufactured by binding strands, particles, fibres, veneers or vegetable fibres together with adhesive to form composite materials of improved quality. These wood and wood products, according to [2], are used as furniture, roofing, flooring, joist, column, pier, cladding and beam materials. Wood and its composites are, at some instances, used in place of steel in many building works. In fact, engineered wood materials are usually employed because of the comparative advantages in its relative low weight, cheapness and durability.

In the process of seasoning, the point at which the free water from cell cavities evaporates, leaving the cell wall still saturated with combined moisture is the Fibre saturation point [2]. Therefore, the workability of wood in the cell walls and cell cavities as illustrated by [2] and [1] are greatly influenced by the absorption process. Timber swells when air becomes moist and shrinks when the air dries. The EMC affect the performance of wood, as the wood continues to absorb or loose moisture in response to changing levels of temperature and humidity. The rate of absorption also need to be controlled to avoid excessive and other forms of defects. A perfectly fit door can distort when installed in an air conditioned or heated house [1]. Indoor jobs should range between $9 \%$ and $8 \%$ while fungus affect wood when it is above the $20 \%$ moisture content upper limit for exterior jobs [5]. Even properly seasoned timbers, if used in damp conditions, can absorb moisture content essential to the growth of fungi. It is important that a green timber should have the $\mathrm{MC}$ reduced to the prevailing $\mathrm{MC}$ percentage, depending on the surrounding EMC and the use to which it is to be put. However, wood is never dried completely to a zero percentage MC but eventually it will reach a level consistent with its environment [1]. And, it will therefore be recommended that work pieces are better kept where they were to be used to acclimatize prior to using them. The functionality and durability of wood and engineered wood materials vary relative to level of exposure and prevalent climatic conditions.

Sized sections of solid wood distort differently depending on growth ring orientation. They shrink and distort very highly across the width, almost twice as much along the line of the annual rings than as it does across it as they lose water contrary to what happens with engineered boards which are more stable since they are, in most cases, not built with defined length or width except as exemplified in the assigned size. Shrinkage, as stated by [1] described the behaviour of timber as it dries. Whereas movement is the tendency of wood to expand or shrink after it has been seasoned depending on its surroundings. Wood species with high stability are less likely 
to deform if the rate of tangential and radial movement are similar [5]. Percentage of shrinkage varies according to the species of wood, volume of water or sap, degree of drying and conversion methods used relative to the position of the grains or the medullary rays of the wood. The greatest working of wood occurs in the direction of the growth rings to cause tangential shrinkages. However, heartwood do not gain or lose moisture like the sapwood because of its rate of moisture permeability. The MC is given as the percentage of its dry weight. Comparing the original weight of a newly-felled piece with the weight of same sample after it has been subjected to a drying process [6], [7], [5] and [1].

Some effects of water absorption on wood and woody materials are: Marine borers found in salty waters causing loss of strength and colour 2. Water rot causing chemical decomposition of wood due to improper seasoning or exposure to rain and wind [6]. 3. Sap stain - caused when sapwood loses its colour due to the cell contents being fed upon by fungi. 4 . Dry rot occurring where there is no air circulation such as improperly ventilated rooms and basements [6]. 5. Blue stain discolouration caused by fungi. 6. Dry wood having less than 12\%-14\% MC remains sound for centuries [5]. 7. Case hardening - the exposed surface of timber drying quickly therefore shrinks and is in compression while the interior surface which is partly dried is under tension [2]. 8. Maximum amount of shrinkage occurring imaginatively along the length of the board and along the grain with less loss over radial directions [5]. 9. Water stain occurring when wood comes in contact with water and get discoloured. 10. Honey combing an irreversible defect occurring when internal stresses causing cracks form honeycomb appearance. 11. Weathering - the physical and chemical breaking-down of the wood structure due to exposure to weather. 12. Destruction due to insect attacks. However, on the positive side, [5] states that because steam softens wood fibres, work piece can be bent into relatively tight curves when they have been steamed. Woodworkers have seized upon this opportunity to create innovative designs from laminated components.

Medium Density Fibreboard is an engineered wood product made by using fine de-fibered wood residuals combined with wax and resin binder to form panels by applying high temperature and pressure [8]. The mix is compacted in a heated press and the end product has a smooth uniform texture [5]. MDF is a stable, dense, stiff material with large defect-free comparatively wide size. MDF has poor moisture resistance, low integral strength and reacts to hydro effect. Reference [1] emphasized that MDF has properties that can be carcinogenic with its dusty particles.

Chipboard is an engineered material made from shredded and pulped wood chips, wood pulp or sawdust and resin-binded for use in furniture and building works. Chipboards are made from wafer-like particles with poor moisture resistance and low integral strength [1]. Chipboard, like other particle boards, is prone to sagging and buckling when exposed to water or extreme moisture. It was stated by [5] that like other wood products, interior-grade chipboard is adversely affected by moisture. The use of moisture resistant adhesive makes the swelling and shrinking during dry and moist seasons negligible [2].
Plywood is an engineered material manufactured from thin layers or piles of wood glued together with adjacent layers at right angles to one another. Plywood is available in both the three ply and the multi-ply thickness which can be manufactured as a WBP (weather and boil proof). [2] expressed that the marine grade plywood which is mostly designed as exterior graded is bonded by using phenolformaldehyde making it highly resistant to water, heat, most chemicals and micro-organisms. Again, [7] stated that plywood does not expand, shrink, warp or twist in the same way as solid timber of the same thickness because of the cross bonding of its veneers. It is mainly used where uniform strength and durability are prime considerations.

Cordia (Cordia millenii) is a solid wood specie of flowering tree in the Boraginaceae family. They are found mostly in warm regions of West Africa and useful for furniture and cabinet making. The sapwood is whitish while the heartwood remains pale brown. Cordia has close and interlocking-grain but fairly light and soft though durable and resistant to termites [9].

Mahogany (Khaya ivorensis) is a genre of solid wood that is highly durable and resists wood rots. It remains pale and pinkish brown with coarse or interlocking grain. Mahogany stands up extremely well to water and is even used to make boats. It resists swelling, shrinking and warping very well [10]. Mahogany is an African hardwood, with excellent workability, that is useful for furniture and cabinet making. The heartwood of a Mahogany do not readily absorb or loose water like its sapwood because of its decreased permeability.

\section{MATERIALS AND METHODOLOGY}

The engineered composite boards used for this research work are: MDF, Plywood and Chipboard (Engineered boards) since they are among the common manufactured boards used in Nigeria while Cordia and Mahogany (solid wood) are also some of the most available wood types in West Africa. All the specimens were of the same dimension of $125 \mathrm{~mm} \times 15 \mathrm{~mm} x$ $15 \mathrm{~mm}$. The timber and composites were subjected to water for three hours duration and their change in moisture content and weight measured at every 30 minutes interval. The digital weighing balance and moisture meter were used in measuring the differential weight and percentage respectively of the specimens at every intervals of one hour. The equipment used are: bucket, moisture meter tester, measuring tape and digital weighing balance. The timber and composites were subjected to water for three hours duration and their change in moisture content and weight equally measured at every 30 minutes interval.

\section{RESULTS AND DISCUSSIONS}

Figure 1 shows the effect of water on both the solid woods (Mahogany and Cordia) and the various engineered boards (plywood, chipboard and medium density fibre boards). All the timbers and composites were immersed fully in water for a total of three hours duration and their change in moisture content and weight measured every one hour. 


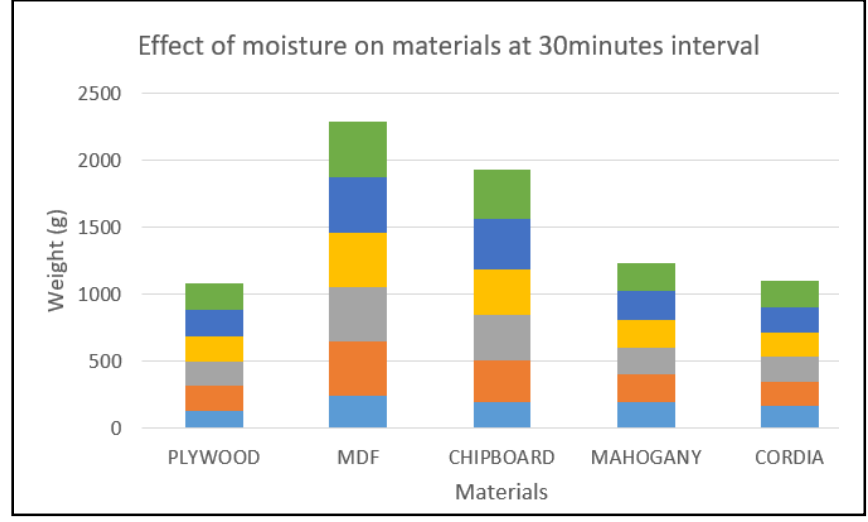

Figure 1: Effects of moisture on wood fibre weight within three (3) hours

From Figure 1, the weight of all the materials increased geometrically during the first one hour but the weight gained in the solid woods still continue while at a point those of the engineered boards stopped because of its loose permeability and having successfully gotten to the peak of its absorption.

The hygroscopic effect stalled early in engineered boards. It was observed that the engineered boards buckle and distort so fast because it has degraded unlike as obtained with solid wood types as observed in figure 2 below.

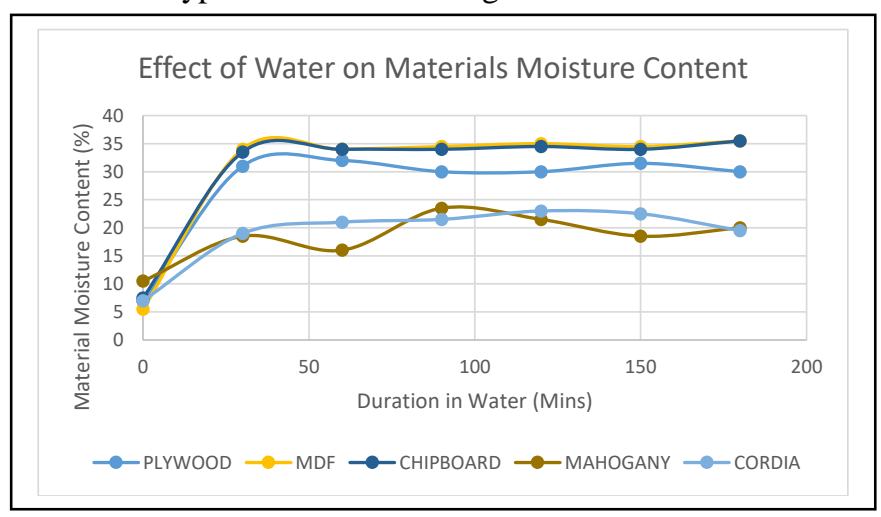

Figure 2: Rate of absorption of water during immersion

Interaction between moisture change and mechanical loading was found to be significant during the first moisture cycle but much smaller during subsequent cycles. [11]. Therefore, it can be safely agreed that the solid woods (Mahogany and Cordia) can actually be used as structural materials for outdoor jobs.

\section{FINDINGS AND CONCLUSION}

This paper researched into the effect of moisture on wood and wood composites as seen in figure 2. The wood composites were subjected to 3 hours full immersion in water and their weight and moisture content were taken at intervals of 30mins consecutively. It was observed that the MDF before immersion was $245 \mathrm{~g}$ but after subjection to water, its weight increased to $401 \mathrm{~g}$ within the first $30 \mathrm{mins}$ of immersion. This implies that an MDF material will absorb water of almost $64 \%$ of its weight on immersion in water within the first $30 \mathrm{mins}$ and less than $1 \%$ increment in subsequent 30 mins interval. It was observed that the Chipboard before immersion was $193 \mathrm{~g}$ in weight but after subjection to water, its weight increased to $310 \mathrm{~g}$ within the first $30 \mathrm{mins}$ of immersion. This implies that a chipboard material will absorb water of almost $60.6 \%$ of its weight on immersion in water within the first 30mins and $8.87 \%$ increment in further 30 mins interval. It was observed that the plywood before immersion was $131 \mathrm{~g}$ in mass but after subjection to water, its weight increased to $181 \mathrm{~g}$ within the first 30mins of immersion. This implies that a plywood material will absorb water of almost $37.89 \%$ of its weight on immersion in water within the first 30minutes and $3.31 \%$ increment in subsequent 30minutes interval.

However, for the solid wood materials, it was observed that Mahogany before immersion was $194.75 \mathrm{~g}$ in weight but after subjection to water, its weight increased to $203 \mathrm{~g}$ within the first 30mins of immersion. This implies that Mahogany material will absorb water of almost $4.28 \%$ of its weight on immersion in water within the first 30 mins and $1.16 \%$ increment in next $30 \mathrm{mins}$ interval and $1.09 \%$ in further $30 \mathrm{mins}$ (i.e. $1 \mathrm{hr} 30 \mathrm{mins}$ in total duration). It was observed that Cordia wood at immersion weighed $194 \mathrm{~g}$ but after subjection to water, its weight increased to $203 \mathrm{~g}$ within the first $30 \mathrm{mins}$ of immersion. This implies that Cordia material will absorb water of almost $10.1 \%$ of its weight on immersion in water within the first $30 \mathrm{mins}$ and $1.67 \%$ increment in subsequent $30 \mathrm{mins}$ interval.

\section{RECOMMENDATION}

Solid woods are more resistant to water absorption than the engineered composite boards. Mahogany and Cordia are especially recommended for outdoor works because of their grains that are not as permeable as the engineered boards such as MDF, plywood and chipboard that are best suited for indoor jobs where exposure to moisture changes are limited. Solid woods (Mahogany and Cordia) were tested to have more resistance to water absorption than as obtained with the engineered materials (plywood, chipboard and medium density fibre boards). However a structural or marine plywood material can comparatively function in an outdoor environment where wood material is not readily available or where size is of utmost importance.

Capitalize only the first word in a paper title, except for proper nouns and element symbols.

For papers published in translation journals, please give the English citation first, followed by the original foreign-language citation [6].

\section{REFERENCE}

[1] S. Corbett. The Complete Practical Woodworker. Leicestershire: Anness Publishing Ltd. 2012

[2] A.J. Walton, Woodwork Theory and Practice $\left(6^{\text {th }}\right.$ ed). Australia: Random House 1990.

[3] Dinwoodie, J.M., Higgins, J.A., Paxton, B.H. et al. (1992) Creep in chipboard Part ii: Wood Science and Technology. 26(6), pp.429 448.

[4] Dinwoodie J.M, Robson D.J., Paxton B.H., Higgins J.S., (1991) Creep in chipboard Wood science and Technology. 25(3) pp225 238.

[5] Albert, J. \& David, D. (2005). Complete Woodworker's Manual. London: Harper Collins Publishers.

[6] Adeniyi, S., Njoku , U.A and Hassan, U. (2013). Machine Woodworking for Senior SecondarySchools and Colleges in Line with NERDC Curriculum. Nigeria, Ibadan: Rasmed Publications Ltd, ISBN: 978-978-51983-8-6. 
[7] Strefford, J. \& Mcmurdo, G. (1996) Woodwork Technology, $9^{\text {th }}$ Ed. England: Netherwood Dalton \& co. Lot.

[8] Spence, W. P., (2005). The Home Carpenters and Woodworkers Repair Manual. New York City: Sterlling. ISBN 1-4027-1055-0 p.114.

[9] Wikipedia contributors. (2019, May 16). Andy Dingley In Wikipedia, The Free Encyclopedia. Retrieved on $16^{\text {th }}$ June, 2019 from https://en.m. wikipedia.org/index. Php? Title = Plywood.
[10] Catherine Florentino (2006). The effects of Water on Different Types of Wood. Retrieved on $16^{\text {th }}$ June, 2019 from https://www.hunker.com.

[11] Martensson, A., Thelandersson, S., (1990) Effect of moisture and mechanical loading on wooden materials Wood Science and Technology, 1990, Vol 24, Number 3, Page 247.

[12] Cambridge University Dictionary, https://is.mendelu.cz/eknihovna/opory/zobraz_cast.pl?cast=19436 